\title{
Effects of Emotional Intelligence on Multi-cultural Cognition and Multi-cultural Attitude in Undergraduate Nursing Students in Korea
}

\author{
Seong Mihyeon ${ }^{1}$, Chung Soojin ${ }^{2}$, Hong Hyonjoo ${ }^{3}$, Song Jihyun ${ }^{4}$, Hwang Wonju ${ }^{5}$ \\ ${ }^{1}$ Department of Nursing, ChangshinUniversity. Assistant Professor, MSN, PhD, ${ }^{2}$ Department of Nursing, Graduate \\ School, Kyung Hee University. Doctoral student, MSN, ${ }^{3}$ National Center for Mental Health, RN, MSN, PhD, \\ ${ }^{4}$ Department of Nursing, Cheju-Halla University. Assistant Professor, MSN, PhD, ${ }^{5}$ College of Nursing Science, \\ Kyung Hee University. Associate Professor, MPH, PhD
}

\begin{abstract}
Introduction: The purpose of this study was to provide basic data to develop effective multicultural education programs related to emotional intelligence by understanding its relationship with multicultural cognition, and the attitude of college students in the nursing science departments.

Method: A descriptive correlational survey design was administered on a total of 197 nursing students in Korea. The collected data were analyzed using descriptive statistics, t-test, ANOVA, and multiple regression analysis, with the SPSS/WIN 21.0 program.

Result: The multicultural perception was $3.61 \pm 0.40$ out of 5 , and the multicultural attitude was $4.52 \pm$ .61 out of 6 . Emotional intelligence which comprises multicultural cognition $(p<.001)$, and multicultural attitude $(p<.001)$, all had a positive correlation with multicultural attitude $(p<.001)$.

Discussion: To develop multicultural education programs for nursing students and college students, it is necessary to develop and apply differentiated intervention strategies using emotional intelligence.

Implications for nursing: This can contribute to promote flexibility of nursing students and help them adapt themselves to clinical practice.
\end{abstract}

Keywords: Emotional Intelligence, Multicultural cognition, Multicultural attitude, Nursing students.

\section{Introduction}

Necessity of the research: Historically, Korea's society shows unity in its characteristics, but this slowly changed as modern society brought about advancement in transportation and communication, along with the

\section{Corresponding Author:}

\section{Wonju Hwang}

College of Nursing Science, Kyung Hee University, 26

Kyungheedae-ro, Dongdaemun-gu, Seoul 02447, Korea

Tel: +82-2-961-0305

Fax: +82-2-961-9398

e-mail: hwangwj@khu.ac.kr exchange of people and goods, which changed the society into a more multicultural one ${ }^{1}$. The result of a survey conducted by the Ministry of Social and Public Administration with a number of foreign residents in Korea shows that long-term foreign residents comprise $3 \%$ of the whole population in Korea ${ }^{2}$.

In order to create a harmonious coexistence between the local society and newcomers, an alteration in the health service providers should be one important matter that should be discussed ${ }^{3}$. However, since the preference of professionals affect the health services provided and causes inequality, it is important that nurses and doctors avoid an exclusive stance and accept the differences within the society ${ }^{4,5}$. Furthermore, healthcare is expanding more multiculturally and is an important 
point in healthcare education. This means that education regarding multiculturalism should be emphasized.

Despite these efforts, there are still existing discriminations and prejudices in the current Korean society, and these views influence the interaction of patients and nurses themselves ${ }^{6,7}$. Therefore, emotional intelligence is an important term that should be viewed in terms of multiculturalism education. Thus people with this characteristic show strength in dealing with biases and controlling their emotions.

Emotional intelligence is the ability to control one's own emotions and understand that of others in different situations $^{8}$. This manifests the optimistic view of the psychological state one is currently in. In the different situations one may be exposed to in the clinical field, this ability is important since one must control one's own feelings and provide healthcare services to the patients. Therefore, this is an important ability that healthcare providers must learn through education ${ }^{9}$.

In some studies, the main factors that affect the Korean university students' perspective of multiculturalism and biases are categorized into personal, tendency, experience, and capability factors. Furthermore, out of these factors, the cultural capability factor is a part of emotional intelligence, and this factor interacts with the following knowledge and the acknowledgement ${ }^{10}$.

Studies show that emotional intelligence is deeply related to self-efficiency, and it plays an intermediary role for problem behaviors. In the same perspective, the relationship between emotional intelligence and personal factors that influence stress and anxiety in healthcare providers in the clinical field is also a growing issue in nursing science $\mathrm{e}^{11,12}$.

Previous research implies that emotional intelligence is related to one's ability to smoothly solve problems and deal with stressful situations ${ }^{13,14}$. Therefore, without any exposure to multiculturalism in the education process, emotional intelligence is thought to have a positive influence on healthcare providers in the clinical field. However, further research on this subject is still insufficient.

Finding and identifying the exact relationship between emotional intelligence and the cognition of multiculturalism is critical in nursing education. In the rapidly changing multicultural medical arena, nursing should be done under the firm implication of a thorough understanding of multiculturalism in all health service providers. It is important that nursing education ensures this is met. Thus, this current study was conducted to determine the actual relationship between emotional intelligence and the development of multiculturalismrelated educational programs.

\section{Research Objective:}

1. To understand the emotional intelligence and the acknowledgement of multiculturalism of nursing students.

2. To realize the difference in emotional intelligence, acknowledgement, and attitude of multiculturalism based on general characteristics of nursing students.

3. To understand the relationship between emotional intelligence and the acknowledgement of multiculturalism.

4. To understand the effects of emotional intelligence on the acknowledgement of multiculturalism

\section{Research Method}

1. Research Design: This study was a descriptive research study with the objective of understanding the effects of emotional intelligence on the acknowledgement of multiculturalism. This study also analyzed the emotional intelligence and the acknowledgement of multiculturalism in nursing students.

2. Research Subject: The participants were nursing students from $\mathrm{S}$ city to $\mathrm{J}$ city. The sample size included 200 people, calculated using the G-power 3.1.1 program. The effect size needed in multiregression analysis was 0.25 , with power $(1-\beta)$ $=0.80$, and significant level $(\alpha)=.5$. The results showed that 180 participants were appropriate, and an elimination rate of $10 \%$ was considered, resulting in a sample of 200 participants. However, in the final analysis, 3 participants were excluded due to missing information and inadequate responses to the survey.

\section{Research Tools:}

1. Emotional Intelligence: Emotional intelligence is a term used to describe the ability to understand one's feelings and those of others, and the acknowledgment of these feelings before getting into action ${ }^{8}$. This study used a scale that was adapted from WLEIS (Wong \& Law's Emotional 
Intelligence Scale ${ }^{15}$ ) by Jung ${ }^{16}$. Permission was granted for its use. This scale consists of 4 questions on self- emotional understanding, 4 questions on emotional understanding of others, 4 questions on emotional control, and 4 questions on emotional application. The Likert Scale is used to rates responses, where $1=$ highly unlikely and $7=$ highly likely. Higher scores indicate higher emotional intelligence. Validity verification was also done, which showed reliability with Cronbach's $\alpha=0.87$ (when the tool was created), and $\alpha=0.89$ (when the research was conducted)

2. Acknowledgement of Multiculturalism: Acknowledgement of multiculturalism is the level measuring how much nurses accept and respect the cultural differences in a society ${ }^{17}$. The tool designed by $\mathrm{Kim}^{18}$ for teenagers was used, and permission for the use of such was granted. Eight questions regarding acceptance of differences, 6 on sensitivity towards differences, and 6 on openness towards differences were asked, totaling to 20 questions. The Likert Scale was used to rate responses, where $1=$ highly unlikely and $5=$ highly likely, with higher scores indicating a higher level of acknowledgement. The scales's validity was measured, with reliability showing Cronbach's $\alpha=0.89$ (when the tool was created), $\alpha=0.82$ (when the study was conducted)

3. Attitude towards multiculturalism: This is an owned property regarding the consistent reaction towards the multicultural society and recognize the cultural difference between various cultures ${ }^{19}$. The tool adapted from MASQUE (Munroe Multicultural Attitude Scale Questionnaire ${ }^{20}$ ) by Kang and $\operatorname{Lim}^{19}$ was used, excluding questions that overlap with questions from the "Acknowledgment of Multiculturalism" portion. Six questions regarding different cognitions, 4 regarding openness and acceptance, and 4 regarding willingness to get in action were included resulting in a total number of 14 questions. A Likert-type scale was used to rate responses, with $1=$ highly unlikely and $6=$ highly likely, with higher scores indicating a more optimistic attitude towards multiculturalism. Validity was measured, with reliability indicating Cronbach's $\alpha=0.89$ (when the tool was created), $\alpha=$ 0.92 (when the study was conducted).

4. Data collection: The data collection period was from December 1, 2016 to March 1, 2017. Before data collection, all participants were informed about the precautions and the data usage. They were informed that data will be used only for research purposes and will be handled anonymously. The participants provided their written informed consent. Furthermore, 10 pre-surveys were done to ensure that the participants fully understood the survey questions.

The research was approved by the research ethics review committee in the institution (approval number: KHSIRB-16-071 (RA)).

5. Data Analysis: The collected data were analyzed using the IBM SPSS/WIN 21.0 program. The degree of the subjects' general properties, emotional intelligence, acknowledgement and attitude towards multiculturalism were expressed using real numbers, average, and standard deviation. The difference between the three terms were found using the Independent t-test and One-way ANOVA. The relationship between the three terms were analyzed using the Pearson's correlation coefficient, and multiple regression analysis was done to determine the effect of emotional intelligence on the acknowledgement and attitude of the participants toward multiculturalism.

\section{Results}

1. The degree of the subjects' emotional intelligence, acknowledgement and attitude towards multiculturalism.

Emotional Intelligence - Out of 7 points, subjects' average $=4.80 \pm 0.72$

Acknowledgement of multiculturalism-Out of 5 points, subjects' average $=3.61 \pm 0.40$

Attitude towards multiculturalism-Out of 5 points, subjects' average $=4.52 \pm 0.61$ (Table 1)

2. The difference between emotional intelligence, acknowledgement and attitude towards multiculturalism based on general properties of subjects

Results showed meaningful differences in emotional intelligence between participants who had experience regarding multiculturalism other than major education and those who had no experience at all. $(\mathrm{t}=2.34, \mathrm{p}=.020)$

Results regarding the difference between degrees of acknowledgement towards multiculturalism regarding the participants' general characteristics showed the 
highest results in grade $2(3.75 \pm 0.46)$, followed by grade $3(3.58 \pm 0.39)$, grade $1(3.56 \pm 0.40)$, and grade $4(3.55 \pm 0.32)(\mathrm{F}=2.84, \mathrm{p}=.039)$. Participants who had experiences of activities regarding multiculturalism had higher scores than those who had no experiences at all $(\mathrm{t}=2.30, \mathrm{p}=.023)$. Participants who had received education on multiculturalism other than their majors had higher scores $(t=2.66, p=.009)$. Those who have friends from different cultures also had higher scores $(\mathrm{t}=2.01, \mathrm{p}=.046)$.

Questions regarding relations with multicultural societies were answered by 1) do not know firsthand, but have talked to them $(3.80 \pm 0.43), 2)$ have known them and lived with them in the same neighborhood (3.72 \pm 0.43$), 3)$ only seen them on TV or in movies (3.58 \pm 0.23 ), and 4) do not know them firsthand, but have seen them in the neighborhood $(3.56 \pm 0.40)(\mathrm{F}=2.50$, $\mathrm{p}=.044)$. Results regarding differences in attitudes towards multiculturalism based on participants' general properties showed higher scores in participants who have experienced various practical trainings than those who have not $(t=3.97, p<.001)$. Higher scores were also recorded in participants who have multi-cultural friends $(t=2.95, p=.010)$. Questions regarding contacts with multicultural societies in the previous year were answered by 1) very often $(3.72 \pm 0.60), 2)$ sometimes $(3.65 \pm 0.39)$, and 3) not at all $(3.52 \pm 0.34)(\mathrm{F}=3.14, \mathrm{p}=.046)$. Questions regarding the necessity of multiculturalism education in the nursing education system were answered by 1) very necessary (3.80 \pm 0.34$), 2)$ a little bit necessary (3.54 $\pm 0.40)$, and 3) so-so $(3.50 \pm 0.39)(\mathrm{F}=8.17, \mathrm{p}<001)$.

1. The relationship between emotional intelligence, acknowledgement and attitude towards multiculturalism: Emotional intelligence is in direct proportion with acknowledgement and attitude (both $\mathrm{p}<.001$ ), while acknowledgement is in direct proportion with attitude $(\mathrm{p}<.001)$. Thus, this means that participants with higher emotional intelligence have higher acknowledgement and positive attitudes, and higher acknowledgement led to more optimistic attitudes. (Table 2).

2. Factors influencing acknowledgement and attitude towards multiculturalism: Multiregression analysis was performed to determine the effects of emotional intelligence on a participant's acknowledgement and attitude towards multiculturalism. The results are shown in Tables 3 and 4 .

Along with emotional intelligence, grades, experience of practical training, education experience, existence of multicultural friends, experience with multicultural members, frequency of contacts with them, and necessity of multiculturalism education were independent variables. The results showed the following: Durbin Watson statistics was 2.039, indicating no influence since the number is close to 2 ; tolerance $=$ 0.661 , lower than 0.1 ; VIF was lower than 10 , thus there were no problems in multicollinearity. The analysis using these independent variables were meaningful $(\mathrm{F}=5.775, \mathrm{p}<.001)$, and estimated the acknowledgement of multiculturalism of nursing students in grade 2, necessity of multicultural education, and emotional intelligence (28.0\%). (Table 3)

Along with attitude towards multiculturalism, practical training experience, existence of multicultural friends, experience with multicultural members, and necessity of multicultural education were independent variables. Results showed the following: Durbin Watson statistics was 1.826 , indicating no influence since the number is close to 2 ; tolerance $=0.715$, lower than 0.1 , VIF was lower than 10, thus there were no problems in multicollinearity. The analysis using these independent variables was significant $(\mathrm{F}=7.422, \mathrm{p}<.001)$. Influence factors were estimated as practical training experience, necessity of multiculturalism education, and emotional intelligence (24.7\%). (Table 4).

Table 1. Emotional Intelligence, Multicultural Awareness and Multicultural Attitude (N=197)

\begin{tabular}{|l|c|c|c|c|}
\hline Variables & Mean \pm SD & Minimum & Maximum & Range \\
\hline Emotional Intelligence & $4.80 \pm 0.72$ & 2.94 & 6.44 & 3.50 \\
\hline Multicultural Awareness & $3.61 \pm 0.40$ & 2.33 & 4.80 & 2.47 \\
\hline Multicultural Attitude & $4.52 \pm 0.61$ & 2.71 & 6.00 & 3.29 \\
\hline
\end{tabular}


Table 2. Correlational Relationships among the Variables $(\mathrm{N}=197)$

\begin{tabular}{|l|c|c|c|}
\hline \multirow{2}{*}{ Variables } & Emotional Intelligence & Multicultural Awareness & Multicultural Attitude \\
\cline { 2 - 4 } & $\mathbf{r}(\boldsymbol{p})$ & $\mathbf{r}(\boldsymbol{p})$ & $\mathbf{r}(\boldsymbol{p})$ \\
\hline Emotional Intelligence & 1 & & \\
\hline Multicultural Awareness & $.40(<.001)$ & 1 & 1 \\
\hline Multicultural Attitude & $.37(<.001)$ & $.69(<.001)$ & \\
\hline
\end{tabular}

Table 3. Factors Influencing Multicultural Awareness (N=197)

\begin{tabular}{|c|c|c|c|c|c|c|}
\hline Variables & B & S.E. & $\boldsymbol{\beta}$ & $\mathbf{t}$ & $\mathbf{p}$ & VIF \\
\hline (Constant) & 3.012 & .418 & & 7.210 & $<.001$ & \\
\hline \multicolumn{7}{|l|}{ Grade* $^{*}$} \\
\hline $1 \mathrm{st}$ & .038 & .070 & .041 & .542 & .588 & 1.555 \\
\hline 2nd & .215 & .072 & .230 & 2.998 & .003 & 1.600 \\
\hline 3 rd & .038 & .068 & .042 & .557 & .578 & 1.584 \\
\hline Experience of clinical practice in of multicultures $\dagger$ & .149 & .104 & .096 & 1.428 & .155 & 1.231 \\
\hline $\begin{array}{l}\text { Experience of multicultural education beside major } \\
\text { curriculum } \dagger\end{array}$ & .066 & .058 & .073 & 1.128 & .261 & 1.133 \\
\hline Foreign friends ${ }^{\S}$ & .063 & .071 & .063 & .890 & .375 & 1.364 \\
\hline \multicolumn{7}{|l|}{ Relationship with foreigner" } \\
\hline Neighborhood well known & .112 & .133 & -.081 & -.842 & .410 & 2.528 \\
\hline Neighborhood not known & -.166 & .101 & -.161 & -1.638 & .103 & 2.620 \\
\hline Not known, but have talked & .055 & .110 & .047 & .500 & .617 & 2.369 \\
\hline Not known, have seen in street & -.097 & .087 & -.122 & -1.112 & .268 & 3.276 \\
\hline \multicolumn{7}{|l|}{ Contact with foreigner } \\
\hline None & -.121 & .107 & -.147 & -1.135 & .258 & 4.575 \\
\hline Sometimes & -.053 & .099 & -.066 & -.531 & .596 & 4.222 \\
\hline \multicolumn{7}{|l|}{ Necessity of nursing education about foreigners ${ }^{\iint}$} \\
\hline None & .068 & .363 & .012 & .187 & .852 & 1.144 \\
\hline Little necessary & -.196 & .064 & -.223 & -3.048 & $<.001$ & 1.464 \\
\hline Necessary & -.241 & .060 & -.295 & -3.996 & $<.001$ & 1.481 \\
\hline Emotional Intelligence & .179 & .036 & .321 & 5.022 & $<.001$ & 1.116 \\
\hline
\end{tabular}

$\mathrm{B}=$ Unstandardized Coefficients; $\mathrm{S} . \mathrm{E}=$ Standard Error; $\beta=$ Standardized Coefficients; $D$ - $W=$ Durbin-Watson Dummy variables: $* 4$ th, $\uparrow$ None, $\$$ None, $\S$ None, $\mathbb{\uparrow N e v e r ~ s e e n ~ e x c e p t ~ o n ~ T V ~ o r ~ m o v i e , ~} \int$ Frequently, $\iint$ Very necessary.

Table 4. Factors Influencing Multicultural Attitude ( $N=197)$

\begin{tabular}{|l|c|c|c|c|c|c|}
\hline Variables & B & S.E. & $\boldsymbol{\beta}$ & t & p & VIF \\
\hline (Constant) & 3.422 & .303 & & 11.294 & $<.001$ & \\
\hline Experience of clinical practice in institute of multicultures* & .505 & .157 & .212 & 3.212 & .002 & 1.137 \\
\hline Foreign friends $^{\dagger}$ & .054 & .108 & .035 & .499 & .618 & 1.294 \\
\hline Relationship with foreigner $^{\dagger}$ & & & & & & \\
\hline Neighborhood well known & .242 & .193 & .114 & 1.248 & .214 & 2.165 \\
\hline
\end{tabular}




\begin{tabular}{|c|c|c|c|c|c|c|}
\hline Variables & B & S.E. & $\boldsymbol{\beta}$ & $\mathbf{t}$ & $\mathbf{p}$ & VIF \\
\hline Neighborhood not known & -.073 & .152 & -.064 & -.481 & .631 & 2.397 \\
\hline Not known, but have talked & .145 & .164 & .080 & .885 & .377 & 2.137 \\
\hline Not known, have seen in street & -.063 & .131 & -.052 & -.482 & .630 & 3.004 \\
\hline \multicolumn{7}{|c|}{ Necessity of nursing education about foreigners ${ }^{\S}$} \\
\hline None & -.375 & .561 & -.044 & -.669 & .504 & 1.106 \\
\hline Little necessary & -.245 & .100 & -.182 & -2.453 & .015 & 1.433 \\
\hline Necessary & -.300 & .094 & -.239 & -3.207 & .002 & 1.447 \\
\hline Emotional Intelligence & .259 & .055 & .303 & 4.729 & $<.001$ & 1.068 \\
\hline
\end{tabular}

$\mathrm{B}=$ Unstandardized Coefficients; $\mathrm{S} . \mathrm{E}=$ Standard Error; $\beta=$ Standardized Coefficients; $D$ - $W=$ Durbin-Watson Dummy variables: *None, $\uparrow$ None, $₫$ Never seen except on TV or movie, $\S$ Very necessary

\section{Discussion}

This study was conducted with the objective of estimating the degree of emotional intelligence, acknowledgement and attitude towards multiculturalism, and finding the correlation between these three terms.

The average emotional intelligence scores of nursing students was $4.80 \pm .72$, which is higher than the results shown in Shin and Park's study ${ }^{13}$ of 4.76 . This was also lower than Song and Shin's study ${ }^{21}$, which had an average score of 4.95 although they used the same research tools. Since the emotional intelligence levels are similar in previous studies, this current study demonstrated that nursing education requires care based on empathy and consideration towards patients, as well as emotional intelligence and intellectual areas in caring for patients. Lee and $\mathrm{Gu}^{22}$ reported that emotional intelligence levels can be heightened through education and training. Thus, an education strategy to enhance emotional intelligence levels is needed for healthcare providers to exert their full abilities in the healthcare field. This is needed for evidence that emotional intelligence is the driving force for nurses to be able to exhibit their professional skills ${ }^{23}$. However, emotional intelligence showed differences based on individuals' social and psychological backgrounds ${ }^{24}$.

Thus, for an exact analysis of the degree of intelligence, a comparison study between nurses and other professionals must be conducted. Multiculturalismrelated education showed meaningful statistical differences in emotional intelligence levels. However, it was difficult to obtain information on all the lectures organized in each university's education process, therefore this was excluded when performing this study. This section may be improved through further discussion and research. Further, additional studies regarding the effects of multiculturalism related education on emotional intelligence levels and acknowledgement of multiculturalism is needed since this research showed statistical differences in that area.

The acknowledgement of multiculturalism was influenced by practical training experience, the existence of multicultural friends, experience with multicultural members, frequency of contact with multicultural members, and the necessity of multiculturalism-related education. On the other hand, attitude was influenced by practical training experience, existence of multicultural friends, experience with multicultural members, and frequency of contact with multicultural members. Kim and Lim's ${ }^{25}$ study indicated this factor being the existence of multicultural friends, and Jeon et al.' ${ }^{26}$ study indicated the factor as being experience with multi-cultural members. These studies both showed similar results with the current study. In the relationship between emotional intelligence, acknowledgement and attitude towards multiculturalism, emotional intelligence was directly proportional to acknowledgement and attitude. On the other hand, acknowledgement was directly proportional to attitude. In other words, acknowledgement could affect attitude, and both could affect emotional intelligence.

The results of this research imply that the influencing factors of acknowledgement and attitude towards multiculturalism are emotional intelligence, necessity of multiculturalism related education, and practical 
training experience. First, emotional intelligence is an influencing factor in the acknowledgement and attitude towards multiculturalism, but comparison is difficult due to the lack of antecedent studies ${ }^{27}$. These results showed that for a successful nursing education to be achieved, an education method for heightening emotional intelligence is essential.

Second, since the necessity of multiculturalismrelated education is also an influencing factor, acknowledgement and attitude-based education is needed for a suitable approach to diversity in the nursing field $^{28}$. This result is similar to Hwang et al.'s study ${ }^{29}$, which showed that multicultural related lectures raised the standard regarding attitudes toward multiculturalism. Therefore, for an effective healthcare and approach, education regarding multiculturalism must be carried out in advance.

Lastly, multiculturalism related practical training is an influencing factor as well. This means that opportunities for nursing students to meet actual multicultural members and interaction with their cultures must be provided during the education process ${ }^{30}$.

This study shows significance in the fact that it provided basic information in designing an education process for nursing students to meet multicultural members and gain the abilities to understand them. To raise levels of acknowledgement and attitude towards multiculturalism, examples (North Korean deserters, married foreign residents, emigrant workers), and policies regarding them must be included in lectures, and an education method to raise emotional intelligence must be developed and included as well.

\section{Conclusion}

The objective of this study was to find out the relationship between emotional intelligence, acknowledgement and attitude towards multiculturalism through comparison between the significant factors. The final results have shown that acknowledgement and attitude are indeed related. Therefore, emotional intelligence is necessary for healthcare providers to take a flexible stance towards multiculturalism and fully understand it.

For further research, the following must be kept in mind. First, a research to create an education program using emotional intelligence for nursing students and to verify them is necessary. Second, this study used only a few nursing students as study participants, so a general statement cannot be applied to all nursing students. Thus, future research should expand the research bounds.

Acknowledgments: The authors would like to thank the students who participated in this study and shared their experiences with us.

Funding: This research received no specific grant from any funding agency in the public, commercial, or not-for-profit sectors.

Declaration of Conflicting Interests: The Author(s) declare(s) that there is no conflict of interest.

\section{References}

1. Shin, SJ. A Study on the social workers' cultural competence for multi-cultural practice. Discourse and Policy in Social Science, 2013;6(2), 61-88.

2. Security Administration. Statistics on the status of foreign residents in local governments in 2016 [online]; 2016. [cited 2018 January 2]. Available from: http://www.mois.go.kr/frt/ bbs/type $010 /$ commonSelectBoardArticle. do?bbsId=BBSMSTR_000000000008 \& $n t t I d=60494$.

3. Reimann JO, Talavera GA, Salmon M, Nuñez JA, Velasquez RJ.Cultural competence among physicians treating Mexican Americans who have diabetes: a structural model.Social Science \& Medicine. 2004;59(11):2195-205.

4. Benjamins MR, Whitman S. Relationships between discrimination in health care and health care outcomes among four race/ethnic groups. Journal of Behavioral Medicine. 2014;37(3):402-13.

5. Chae DH, Park YH, Kang KH, Lee TH. A study on factors affecting cultural competency of general hospital nurses. Journal of Korean Academy of Nursing Administration. 2012;18(1):76-86.

6. Glittenberg JA. Transdisciplinary, transcultural model for health care. Journal of Transcultural Nursing. 2004;15(1):6-10.

7. Kang HY, Han SY. A study on social distance of nursing students toward minority groups in a Metropolitan city. Journal of Korean Public Health Nursing 2013;27(1):166-78.

8. Nam KA, Jeong GH. Analysis of prejudice toward foreigners by nurses and physicians in Korea. Journal of Korean Public Health Nursing. 
2013;27(3):437-49.

9. Goleman D. Emotional intelligence. New York: Bantam Books; 1995.

10. SunGok YH, Park SD, Lee YS. Research trends on multicultural perception and attitude of Korean college Students. Multiculture \& Peace. 2013;7(2):173-203.

11. Lee KH, Song JS. The Effect of emotional intelligence on self-efficacy and job stress of nurses-mediating role of self-efficacy. Journal of Korean Academy of Nursing Administration. 2010;16(1):17-25.

12. Downey L, Johnston P, Hansen K, Birney J, Stough C. Investigating the mediating effects of emotional intelligence and coping on problem behaviours in adolescents. In Austin EH and Saklofske DH (eds). Emotional Intelligence. Australian Journal of Psychology. 2010;62(1):20-9.

13. Shin EJ, Park YS. Emotional intelligence, ego resilience, stress in clinical practice of nursing students. Journal of the Korea Academia-Industrial Cooperation Society.2013;14(11):5636-45.

14. Yang SY. The effect of emotional intelligence and self-efficacy on clinical competence of the nursing students. The Journal of The Korea Contents Association. 2015;15(6):370-8.

15. Wong CS, Law KS. The effects of leaders and follower emotional intelligence on performance and attitude: An exploratory study. The Leadership Quarterly. 2002;13(3):243-74.

16. Jung HY. Effectiveness of emotional leadership and emotional intelligence of foodservice employees on organizational performance in contracted food service management company [dissertation]. [Seoul]: Yonsei University; 2006.

17. Kim JA, Choi J. Correlation and influencing factors of multicultural awareness and cultural sensitivity among Korean nursing students. Journal of Multicultural Education Studies. 2016;9(4):67-88.

18. Kim NY. Development and validation of the multicultural awareness scale for adolescents [master's thesis]. [Seoul]: Sung Kyun Kwan University; 2012.

19. Kang HJ, Lim EM. Validation study of multicultural attitude scale for Korean university students. Asian Journal of Education. 2012;13(4):35-57.

20. Munroe A, Pearson C. The Munroe multicultural attitude scale questionnaire: a new instrument for multicultural studies. Educational and Psychological Measurement. 2006; 66(5):819-34.

21. Song HY, Shin SH. The effects of emotional intelligence on the career decision-making selfefficacy and career decision levels of the nursing students. Journal of the Korea Academia-Industrial Cooperation Society. 2016;17(9):628-40.

22. Lee OS, Gu MO. Development and effects of emotional intelligence program for undergraduate nursing students: mixed method research. Journal of Korean Academy of Nursing. 2014;44(6):68296.

23. Beydler KW. The role of emotional intelligence in perioperative nursingand leadership: Developing skills for improved performance. AORN Journal. 2017;106(4):317-23.

24. Afolabi OA. Roles of personality types, emotional intelligence and gender differences on prosocial behavior. Psychological Thought. 2013;6(1):12439.

25. Kim NH, Lim SY. Relationships between multicultural awareness, multicultural attitude and multicultural efficacy among nursing students. Journal of Multicultural Education Studies. 2014;7(4):169-84.

26. Jeon MS, Kim HJ, Ka YR, Kim JW, Kim JS, Park $\mathrm{SH}$, et al. Recognition and attitude of multiculture in undergraduate students. Journal of the Korean Society for Multicultural Health. 2013;3(1):9-14.

27. Ponterotto JG, Ruckdeschel DE, Joseph AC, Tennenbaum EA, Bruno A. Multicultural personality dispositions and trait emotional intelligence: an exploratory study. The Journal of Social Psychology. 2011;151(5):556-76.

28. Beard KV. Examining the impact of critical multicultural education training on the multicultural attitudes, awareness and practices of nurse educators. Journal of Professional Nursing. 2016;32(6):439-48.

29. Hwang HY, Chyn YE, Hur J. Effects of multicultural understanding subject on the empathy and multicultural attitude of nursing student. Journal of the Korea Academia Industrial Cooperation Society. 2015;16(1):106-15.

30. Kim JH. A study about cultural sensitivity and stereotype about immigrant women among nursing students. Journal of Digital Convergence. 2014;12(7):305-14. 